\title{
Solubility of Fudosteine in Some Pure and Mixed Solvents from (278.15 to 308.15$) \mathrm{K}$
}

\author{
Fan-Yong Yan*, Meng Wang, Jing-Yun Wen, Yang Fu and Li Chen
}

State Key Laboratory of Hollow Fiber Membrane Materials and Processes, Key Lab of Fiber Modification \& Functional Fiber of Tianjin, Tianjin Polytechnic University, Binshui West Road, 399, Tianjin 300387, PR. China

\begin{abstract}
The solubility of fudosteine has been determined in pure methanol, ethanol, water and in mixed solvents of methanol + water and ethanol+ water over the temperature range of (278.15 to 308.15$) \mathrm{K}$ at atmosphere pressure. The solubility is high in water, lower in ethanol. In the binary mixtures, the solubility of fudosteine increases with increasing concentration of water. The solubility of fudosteine increases with increasing temperature. The temperature dependence on the solubility data was well-correlated with the modified Apelblat equation, which could be used as a useful model for the purification process of fudosteine.
\end{abstract}

Keywords: Fudosteine, solubility, Apelblat equation, crystallization.

\section{INTRODUCTION}

Fudosteine ((-)-(R)-2-amino-3-(3-hydroxypropylthio) propionic acid, CAS RN: 13189-98-5), also called Spelear, Cleanal, SS-320A, S-(3-Hydroxypropyl)-Lcysteine, a new cysteine derivative that was approved in Japan in 2001, is a unique broad-spectrum, lowmolecular-weight mucoactive agent which inhibits the synthesis of bacterial cell walls by preventing the peptidoglycan synthesis [1, 2]. The molecular structure of fudosteine is illustrated in Figure 1. Fudosteine has been reported to inhibit LPS-induced goblet cell hyperplasia in rat lungs and humans and enhance ciliary beat impaired under cigarette smoke in vitro [35]. Fudosteine also has a therapeutic effect against mucus hypersecretion caused by an increase as the number of goblet cells in chronic respiratory diseases such as bronchial asthma, chronic bronchitis, pulmonary emphysema, bronchiolectasis, pulmonary tuberculosis, pneumonoconiosis, atypical mycobacterial disease and diffuse panbronchitis [6-8]. For pharmaceutical use, fudosteine was usually crystallized from solution purification [9]. Crystallization processes were the key steps that determined the quality of the final product. The solubility of solid compounds in solvents played a crucial role for the determination of proper solvents and the development and operation of crystallization processes. Moreover, solubility is an important physicochemical parameter in the process of drug discovery and development. Therefore, knowing the solubility of the product was necessary. In fact, the solubility of fudosteine in

*Address corresponding to this author at the State Key Laboratory of Hollow Fiber Membrane Materials and Processes, Key Lab of Fiber Modification \& Functional Fiber of Tianjin, Tianjin Polytechnic University, Binshui West Road, 399,Tianjin 300387, PR. China; Tel: 86 (0)22 83955766; Fax: 86 (0)22 83955766; E-mail: yfytju@yahoo.com common solvents or binary solvent mixture was scarcely reported.<smiles>N[C@@H](CSCCCO)C(=O)O</smiles>

Figure 1: Molecular structure of fudosteine.

In the present study, the solubility of fudosteine in pure methanol, ethanol, water and the binary solvent mixtures of methanol + water and ethanol + water was measured within the temperature range from $278.15 \mathrm{~K}$ to $308.15 \mathrm{~K}$ at atmosphere pressure. To obtain more precise solubility data, an analytical method was used, using high-performance liquid chromatography (HPLC) $[10,11]$. The experimental solubility data have been correlated by the Apelblat equation [12].

\section{EXPERIMENTAL SECTION}

\section{A. Reagents and Apparatus}

Fudosteine $\left(\mathrm{C}_{6} \mathrm{H}_{13} \mathrm{NO}_{3} \mathrm{~S}\right.$, relative molar mass 179.23) of pharmaceutical purity grade, was kindly provided Beijing Yue Kang Co. Ltd (China). Its mass fraction was better than $99.5 \%$, determined by highperformance liquid chromatography (Waters Brezze Model). The melting point of fudosteine was $473.25 \mathrm{~K}$, which was measured using a differential scanning calorimeter (DSC, TA SDT Q600). Other reagents are the following: methanol (Tianjin Fuyu Finechem. Co. Ltd., China), ethanol (Tianjin Chemical Reagent Co. Ltd., China). The solvents used for experiments were of analytical reagent grade and dehydrated with molecular sieves ( 3 to 4$) \AA$ before use. The purities (mass fraction) of the solvents were higher than 99.8 mass \%. 


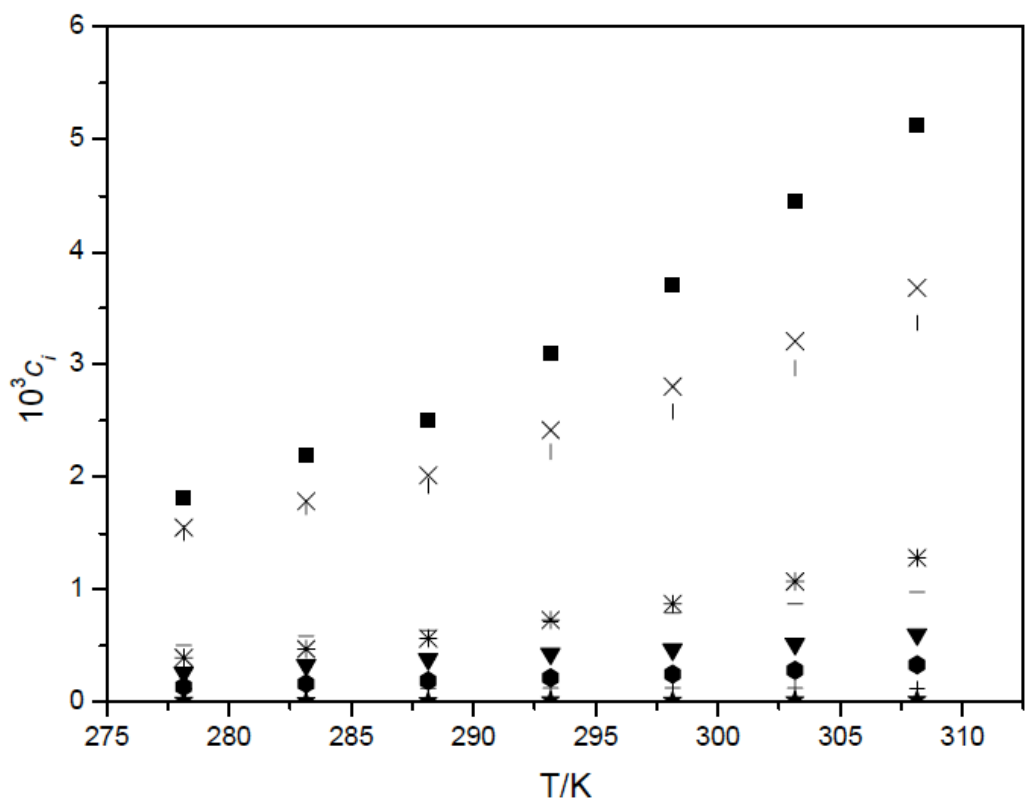

Figure 2: Mole fraction solubility of Fudosteine $\left(\mathrm{c}_{\mathrm{i}}\right)$ in different solvents from 278.15 to $308.15 \mathrm{~K}$. $\mathbf{\square}$ water; $\times 25 \% \mathrm{Methanol}+$ Water; I $25 \%$ Ethanol + Water; - $50 \%$ Methanol + Water; $※ 50 \%$ Ethanol + Water; $75 \%$ Methanol + Water; $75 \%$ Ethanol + Water; + Methanol; $\star$ Ethanol.

Pure water was produced by NANO pure diamond UV/UF (Thermo Scientific Barnstead, USA). The masses of the samples and solvents were determined by an analytical balance (Mettler Toledo AB204-N, Switzerland) with an accuracy of $0.0001 \mathrm{~g}$.

\section{B. Sample Preparation}

Excess amounts of fudosteine crystals were added to $30 \mathrm{~cm}^{3}$ (uncertainty of $\pm 0.1 \mathrm{~cm}^{3}$ ) of pure methanol, ethanol, water and the binary solvent mixtures of methanol + water and ethanol + water at a room temperature of $293.15 \mathrm{~K}$. Then they were directly placed in the shaker where the temperatures were controlled by a thermostat ranging from (278.15 to $308.15) \mathrm{K}$ with each step of $5.0 \mathrm{~K}$ and a temperature uncertainty of $0.1 \mathrm{~K}$. The suspended solution was kept shaken for $24 \mathrm{~h}$ to ensure solid-liquid equilibrium and stabilization of the configuration of fudosteine before sampling. Then the solution was allowed to settle for $0.5 \mathrm{~h}$ in the shaker. The supernatant liquid was withdrawn, filtered through a $0.45 \mu \mathrm{m}$ membrane to avoid entrainment of the solids, appropriately diluted, and analyzed for fudosteine using the HPLC. Each measurement was repeated three times.

\section{Sample Analysis}

The solubility of fudosteine was monitored by reverse-phase separation of a gradient HPLC system (Waters Brezze Model, USA; Pump: Waters 1525 Binary Solvent Delivery System; Detector: Waters 2487 dual $\lambda$ absorbance detector; Integrator: Brezze System Software, and $20 \mu \mathrm{L}$ injector loop). The chromatographic analysis was performed on a Diamonsil C18 column $(250 \mathrm{~mm} \times 4.6 \mathrm{~mm}, 5 \mu \mathrm{m})$, with mobile phase composed of $\mathrm{H}_{2} \mathrm{O}-\mathrm{MeOH}$ (95: 5), the detection wavelength was $220 \mathrm{~nm}$, the flow rate was $0.8 \mathrm{~mL} / \mathrm{min}$, the column temperature was $30{ }^{\circ} \mathrm{C}$. The reference standard solution containing about 0.20 $\mathrm{mg} \cdot \mathrm{mL}^{-1}$ of fudosteine was prepared in methanol. The limit of detection was $0.40 \mathrm{ng}(\mathrm{S} / \mathrm{N}=3)$ The average recovery $(n=3)$ was $98.95 \%(R S D=0.3 \%), 98.93 \%$ $(\mathrm{RSD}=0.8 \%)$ and $98.93 \%(\mathrm{RSD}=0.7 \%)$.

\section{RESULTS AND DISCUSSION}

The mole fraction solubility of fudosteine in the binary solvent mixtures at different temperatures was measured and presented in Table 2 and plotted in Figure 2. According to the Table 2, the solubility in all binary solvent mixtures increases with temperature. We can draw a conclusion that the solubility of fudosteine decreased with an increase of methanol or ethanol content in the mixed solvents and increased with the increase of temperature within the range of (278.15 to 308.15) K.

The experimental solubility of fudosteine as a function of temperature could be computed by the modified Apelblat equation deduced from the solidliquid phase equilibrium as follows: 


$$
\ln c^{\text {calcd }}=A+\frac{B}{T / K}+C \cdot \ln T / K
$$

Where $\mathrm{mol} \cdot \mathrm{dm}^{-3}$ ) is the molar so (ubility of fudosteine, A, B, and C are the empirical constants, and $\mathrm{T}$ is the absolute temperature.

The difference between experimental and calculated results is presented in Tables $\mathbf{1}$ and 2 . The correlated values of parameters $A, B$, and $C$ were presented in Tables 3 and 4 together with the rootmean-square deviation ( $\mathrm{rmsd}$ ) which is defined as:

$r m s d=\left\{\frac{1}{N} \sum_{i=1}^{N}\left(c_{i}^{c a l c d}-c_{i}^{\exp t l}\right)^{2}\right\}^{1 / 2}$

Where $\mathrm{N}$ is the number of experimental points and

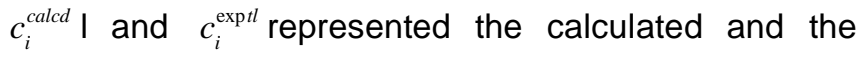
experimental solubility values, respectively.
From Tables $\mathbf{1}$ to $\mathbf{4}$, it could be seen that the calculated solubilities showed good agreement with experimental values, indicating the modified Apelblat equation could be applied to correlate the solubility data of fudosteine in the pure methanol, ethanol, water and in mixed solvents of methanol + water and ethanol+ water. The experimental solubility and the modified Apelblat equation with the parameters might be used as essential data in the purification and crystallization of fudosteine.

\section{CONCLUSIONS}

From Tables $\mathbf{1}$ to $\mathbf{4}$ and Figure 2, we can draw the following conclusions: (1) The solubility of fudosteine in water, methanol and ethanol is a functionof temperature, and it increases with an increase in temperature. The best solubility of fudosteine is shown in water. (2) For methanol + water and ethanol + water binary mistures, the solubility of fudosteine decreased

Table 1: Solubilities (c) of Fudosteine in Water, Methanol and Ethanol from (278.15 to 308.15$) \mathrm{K}$

\begin{tabular}{|c|c|c|c|c|c|c|}
\hline \multirow{3}{*}{$\frac{T}{K}$} & \multicolumn{2}{|c|}{ Methanol } & \multicolumn{2}{|c|}{ Ethanol } & \multicolumn{2}{|c|}{ Water } \\
\hline & \multirow{2}{*}{$\frac{10^{3} \mathrm{c}}{\mathrm{mol} \cdot \mathrm{dm}^{-3}}$} & \multirow[b]{2}{*}{$10^{2}\left(c-c^{\text {calc }}\right) / c^{a}$} & \multirow{2}{*}{$\frac{10^{3} \mathrm{c}}{\mathrm{mol} \cdot \mathrm{dm}^{-3}}$} & \multirow[b]{2}{*}{$10^{2}\left(c-c^{\text {calc }}\right) / c$} & \multirow{2}{*}{$\frac{10^{3} \mathrm{c}}{\mathrm{mol} \cdot \mathrm{dm}^{-3}}$} & \multirow[b]{2}{*}{$10^{2}\left(c-c^{\text {calc }}\right) / c$} \\
\hline & & & & & & \\
\hline 278.15 & 0.121 & 2.78 & 0.011 & 1.01 & 1.818 & -0.05 \\
\hline 283.15 & 0.121 & 1.63 & 0.012 & 1.25 & 2.191 & 0.59 \\
\hline 288.15 & 0.122 & 1.30 & 0.013 & 0.29 & 2.500 & -4.10 \\
\hline 293.15 & 0.124 & 1.76 & 0.015 & 5.03 & 3.102 & -0.06 \\
\hline 298.15 & 0.126 & 2.21 & 0.016 & 1.72 & 3.705 & 0.29 \\
\hline 303.15 & 0.127 & 1.88 & 0.017 & -2.51 & 4.449 & 1.36 \\
\hline 308.15 & 0.128 & 1.55 & 0.020 & 3.08 & 5.122 & -1.59 \\
\hline
\end{tabular}

${ }^{a} c^{\text {calc: }}$ : calculated value based on eq 1 correlated from the experimental solubility of fudosteine in the three solvents.

Table 2: Solubilities of Fudosteine in Different Compositions of Methanol + Water and Ethanol + Water Mixtures from (278.15 to 308.15$) \mathrm{K}$

\begin{tabular}{|c|c|c|c|c|c|c|c|c|c|c|c|c|}
\hline \multirow{4}{*}{$\frac{T}{K}$} & \multicolumn{6}{|c|}{ Methanol + Water } & \multicolumn{6}{|c|}{ Ethanol + Water } \\
\hline & \multicolumn{2}{|c|}{$X=0.250$} & \multicolumn{2}{|c|}{$X=0.500$} & \multicolumn{2}{|c|}{$X=0.750$} & \multicolumn{2}{|c|}{$X=0.250$} & \multicolumn{2}{|c|}{$X=0.500$} & \multicolumn{2}{|c|}{$X=0.750$} \\
\hline & $10^{3} c$ & $10^{3}$ & $10^{3} c$ & $10^{3}$ & $10^{3} c$ & $10^{3}$ & $10^{3} c$ & $10^{3}$ & $10^{3} c$ & $10^{3}$ & $10^{3} \mathrm{c}$ & $10^{3}$ \\
\hline & $\mathrm{mol}_{3} \mathrm{dm}^{-}$ & $\left.c^{\text {calc }}\right) / c$ & $\underset{3}{\mathrm{~mol} \cdot \mathrm{dm}^{-}}$ & $\left.c^{\text {calc }}\right) / c$ & $\mathrm{~mol} \cdot \mathrm{dm}^{-3}$ & $\left.c^{\text {calc }}\right) / c$ & $\underset{3}{\mathrm{~mol}} \cdot \mathrm{dm}^{-}$ & $\left.c^{\text {calc }}\right) / c$ & $\begin{array}{c}\mathrm{mol} \cdot \mathrm{dm} \\
3\end{array}$ & $\left.c^{\text {calc }}\right) / c$ & $\begin{array}{c}\mathrm{mol} \cdot \mathrm{dm} \\
3\end{array}$ & $\left.c^{\text {calc }}\right) / c$ \\
\hline 278.15 & 1.552 & -0.68 & 0.503 & -3.99 & 0.262 & -6.47 & 1.501 & 3.56 & 0.393 & 2.60 & 0.135 & -5.08 \\
\hline 283.15 & 1.786 & -1.88 & 0.588 & 0.315 & 0.329 & 2.91 & 1.731 & 3.71 & 0.473 & 0.41 & 0.165 & 0.44 \\
\hline 288.15 & 2.015 & -4.91 & 0.635 & -3.15 & 0.381 & 4.23 & 1.922 & 0.30 & 0.566 & -2.12 & 0.187 & -1.66 \\
\hline 293.15 & 2.417 & -1.38 & 0.715 & -2.09 & 0.428 & 2.85 & 2.223 & 1.07 & 0.731 & 3.27 & 0.215 & -2.26 \\
\hline 298.15 & 2.806 & -0.99 & 0.794 & -2.19 & 0.469 & -0.79 & 2.58 & 2.32 & 0.872 & 1.07 & 0.248 & -2.46 \\
\hline 303.15 & 3.205 & -2.04 & 0.873 & -3.07 & 0.517 & -3.71 & 2.969 & 2.89 & 1.072 & 2.09 & 0.284 & -3.33 \\
\hline 308.15 & 3.682 & -2.28 & 0.977 & -1.88 & 0.601 & -0.97 & 3.37 & 2.26 & 1.282 & 0.65 & 0.333 & -1.69 \\
\hline
\end{tabular}

${ }^{\mathrm{a}} \mathrm{V}_{1}=\mathrm{V}_{\text {Methanol }}$ or $\mathrm{V}_{\text {ethanol }} ; \mathrm{V}_{2}=$ Water $; \mathrm{X}=\mathrm{V}_{1} /\left(\mathrm{V}_{1}+\mathrm{V}_{2}\right)$ 
Table 3: Parameters of Equation 1 for Fudosteine in Different Pure Solvents in the Temperature Range of (278.15 to 308.15) K

\begin{tabular}{|c|c|c|c|c|}
\hline solvents & $\begin{array}{c}\boldsymbol{A} \\
\mathbf{m o l} \cdot \mathbf{d m}^{-\mathbf{3}}\end{array}$ & $\begin{array}{c}\boldsymbol{B} \\
\mathbf{m o l} \cdot \mathbf{d m}^{-\mathbf{3}} \cdot \mathbf{K}^{-\mathbf{1}}\end{array}$ & $\begin{array}{c}\mathbf{C} \\
\mathbf{m o l} \cdot \mathbf{d m}^{-\mathbf{3}}\end{array}$ & 13.81 \\
\hline \hline Water & -80.86 & 1038.44 & 0.98 & 0.0549 \\
\hline Methanol & -7.98 & 90.19 & 26.26 & 0.0024 \\
\hline Ethanol & -174.02 & 6037.11 & 0.0004 \\
\hline
\end{tabular}

Table 4: Parameters of Equation 1 for Fudosteine in Binary Methanol + Water, and Ethanol + Water Mixtures in the Temperature Range of (278.15 to 308.15$) \mathrm{K}^{\mathrm{a}}$

\begin{tabular}{|c|c|c|c|c|c|}
\hline \multirow{2}{*}{\multicolumn{2}{|c|}{ Solvent }} & \multirow{2}{*}{$\begin{array}{c}\mathrm{A} \\
\mathrm{mol} \cdot \mathrm{dm}^{-3}\end{array}$} & \multirow{2}{*}{$\frac{\mathrm{B}}{\mathrm{mol} \cdot \mathrm{dm}^{-3} \cdot \mathrm{K}^{-1}}$} & \multirow{2}{*}{$\frac{\mathrm{C}}{\mathrm{mol} \cdot \mathrm{dm}^{-3}}$} & \multirow{2}{*}{$10^{3} \mathrm{rmsd}$} \\
\hline & & & & & \\
\hline \multirow{3}{*}{ Methanol + Water } & $X=0.250$ & -53.98 & 266.69 & 9.50 & 0.0589 \\
\hline & $X=0.500$ & -19.09 & -740.89 & 3.75 & 0.0185 \\
\hline & $X=0.750$ & -40.99 & -131.23 & 7.14 & 0.0131 \\
\hline \multirow{3}{*}{ Ethanol + Water } & $X=0.250$ & -62.33 & 767.70 & 10.65 & 0.0589 \\
\hline & $X=0.500$ & -81.00 & 612.56 & 13.83 & 0.0145 \\
\hline & $X=0.750$ & -90.48 & 1783.55 & 14.59 & 0.0059 \\
\hline
\end{tabular}

with an increase of methanol or ethanol content in the mixed solvents and increased with the increase of temperature in the range of $(278.15$ to 308.15$) \mathrm{K}$. In wiew of low toxicity and low price, ethanol + water could be the most suitable binary solvents for purification and crystallization. (3) The calculated solubility of fudosteine sets a good coherence with the experimental values. The solubility data were wellcorrelated with the modified Apelblat equation, which could be used as a useful model in the purification process of fudosteine.

\section{ACKNOWLEDGEMENT}

The authors are grateful for the financial support from the National Natural Science Foundation (Grant No. 20774604)

\section{REFERENCES}

[1] Takahashi $K$, Mizuno $H$, Ohno $H$, Kai $H$, Isohama $Y$, Takahama $\mathrm{K}$, et al. Effects of SS320A, A new cysteine derivative, on the change in the number of goblet cells induced by isoproterenol in rat tracheal epithelium. Jpn J Pharmacol 1998; 77: 71-77. http://dx.doi.org/10.1254/jip.77.71

[2] Nagaoka S, Takishima T, Nagano H, Kawakami Y, Kitamura S, Kawakami M, et al. Phase III Clinical Study of SS320A. Double-blind Trial in Comparison with Placebo. J Clin Ther Med 2002; 18: 109-40.
[3] Takahashi K, Kai H, Mizuno H, Koda T, Miyata T. Effect of fudosteine, A new cysteine derivative, on mucociliary transport. J Pharm Pharmacol 2001; 53: 911-14. http://dx.doi.org/10.1211/0022357011776090

[4] Xu FQ, Zhang ZJ, Jiao HY, Tian Y, Zhang BB, Chen Y. Quantification of fudosteine in human plasma by highperformance liquid chromatography- electrospray ionization mass spectrometry employing precolumn derivatization with 9-fluorenylmethyl chloroformate. J Mass Spectrom 2006; 41: 685-92. http://dx.doi.org/10.1002/jms.1028

[5] Rhee CK, Kang CM, You MB, Yoon HK, Kim YK, Kim KH, et al. Effect of fudosteine on mucin production. Eur Respir $\mathrm{J}$ 2008; 32: 1195-202. http://dx.doi.org/10.1183/09031936.00018508

[6] Wen J, Wu YW, Zhang LL, Qi YP, Fan GR, Wu YT, et al. High-throughput determination of fudosteine in human plasma by liquid chromatography-tandem mass spectrometry, following protein precipitation in the 96-well plate format. J Chromatogr B 2008; 867: 153-59. http://dx.doi.org/10.1016/j.jchromb.2008.03.017

[7] Osoata GO, Hanazawa T, Brindicci C, Ito M, Barnes PJ, Kharitonov $\mathrm{S}$, et al. Peroxynitrite Elevation in Exhaled Breath Condensate of COPD and Its Inhibition by Fudosteine. CHEST 2009; 135: 1513-20.

\section{http://dx.doi.org/10.1378/chest.08-2105}

[8] Komatsu H, Yamaguchi S, Komorita N, Goto S, Takagi H, Ochi $\mathrm{H}$, et al. Inhibition of endotoxin- and antigen-induced airway inflammation by fudosteine, a mucoactive agent. Pulm Pharmacol Ther 2005; 18: 121-27. http://dx.doi.org/10.1016/j.pupt.2004.11.002

[9] Itoh $\mathrm{Y}$, Mizuno $\mathrm{H}$. Expectorant Comprising Hydroxyalkylcysteine Derivative. U.S. Patent 5,047,428, Sep 10, 1991.

[10] Zuo WS, Xu JH. Solubility of Camellianin A in Methanol, Acetonitrile, Acetone, and Water from (283.2 to 313.2) K. J Chem Eng Data 2010; 55: 1372-73. http://dx.doi.org/10.1021/je900554r 
[11] Peng B, Yan WD. Solubility of Luteolin in Ethanol + Water Mixed Solvents at Different Temperatures. J Chem Eng Data 2010; 55: 583-85. http://dx.doi.org/10.1021/je900381r

[12] Apelblata A, Manzurola E. Solubilities of o-aeetylsalicylic, 4ami-nosalicylic, 3, 5-dinitrosalicylic, and P-toluic acid and
magnesium-DL-aspartate in water from $T=278$ to $348 \mathrm{~K}$. J Chem Thermodyn 1999; 31: 85-91.

http://dx.doi.org/10.1006/jcht.1998.0424

Received on 29-10-2012 